\title{
Valor nutricional do mel e pólen de abelhas sem ferrão da região amazônica.
}

\author{
Rosa Cristina da Silva SOUZA ${ }^{1}$, Lucia Kiyoko Ozaki YUYAMA² Jaime Paiva Lopes AGUIAR ${ }^{2}$, Francisco Plácido \\ Magalhães OLIVEIRA. ${ }^{4}$
}

\section{RESUMO}

Avaliou-se os constituintes nutricionais de amostras do mel e pólen das espécies Melipona seminigra merrillae (jandaíra), Melipona compressipes manaosensis (jupará), Melipona rufiventris paraensis (uruçu boca de ralo), provenientes do meliponário da Fazenda Poranga no município de Itacoatiara - AM e Meliponário Abelhudo em Manaus - AM. Os resultados demonstraram o potencial do mel como fonte de energia, particularmente a M. rufiventris com 305,3 $\pm 2,4 \mathrm{kcal} \mathrm{em} 100 \mathrm{~g}$.

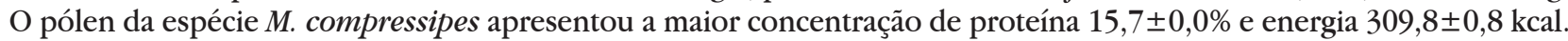
Tais constatações sugerem a implementação de novos estudos visando à incorporação destes produtos na dieta dos amazônidas, possibilitando uma nova fonte alternativa de alimento potencialmente nutritivo e saudável.

\section{PALAVRAS-CHAVE}

mel, pólen, energia, proteína, lipídio

\section{Nutricional value of boney and pollen of stingerless bees of the amazonian region.}

\begin{abstract}
We evaluated the nutricional constituent of honey and pollen samples of the Melipona species seminigra merrillae (jandaíra) Melipona compressipes manaosensis (jupará), Melipona rufiventris paraensis (uruçu boca de ralo), proceeding from the Poranga Honey Farm in Itacoatiara - AM, and Meliponário Abelbudo in Manaus, AM. The results demonstrated the potencial of honey as a source of energy, particularly the kcal M. rufiventris with $305.3 \pm 2.4 \mathrm{kcal}$ in $100 \mathrm{~g}$. The compressis pollen of species presented the highest concentration of protein $15.7 \pm 0.0 \%$ and energy $309.8 \pm 0.8 \mathrm{kcal}$. Thus we suggest the implementation of new studies aiming at the incorporation of these products in the diet of the Amazon population, making possible a new potentially nutritional and alternative bealthful food source.
\end{abstract}

\section{KEY WORDS}

boney, pollen, energy, protein, lipid.

O conhecimento da composição química de nutrientes em alimentos é de fundamental importância para o estabelecimento de dietas adequadas aos indivíduos, para a recomendação de uma alimentação balanceada a grupos populacionais e desenvolvimento de novos produtos (Lajolo, 1995). Apesar dos avanços em relação à quantificação dos constituintes nutricionais dos alimentos da região amazônica (Aguiar, 1996, Yuyama et al., 1997), pouco se sabe sobre o mel e pólen de abelhas sem ferrão.
No Amazonas, o interesse pela criação de abelhas sem ferrão justifica-se pelo alto valor terapêutico do mel e pólen, pela promoção do aumento da renda familiar, polinização e perpetuação de milhares de plantas (Kerr et al., 1996). Além de servir como fonte de lazer, há muito que se estudar em relação aos constituintes nutricionais e farmacológicos. O mel, pólen, geoprópolis e cera de abelha sem ferrão tem sido utilizados pelos índios e sitiantes no combate às doenças pulmonares, inapetência, infecção dos olhos,

${ }^{1}$ Bolsista PCI do Instituto Nacional de Pesquisas da Amazônia da Coordenação de Pesquisas em Ciência da Saúde. Av. André Araújo 2936, Petrópolis, Manaus, AM. CEP. 69083-000

${ }^{2}$ Orientador e pesquisador do Instituto Nacional de Pesquisas da Amazônia da Coordenação de Pesquisas em Ciência da Saúde. Av. André Araújo 2936, Petrópolis, Manaus, AM. CEP. 69083-000. e mail: yuyama@inpa.gov.br. Correspondência para Lucia K.O. Yuyama.

${ }^{3}$ Co-orientador e pesquisador do Instituto Nacional de Pesquisas da Amazônia da Coordenação de Pesquisas em Ciência da Saúde. Av. André Araújo 2936, Petrópolis, Manaus, AM. CEP. 69083-000

${ }^{4}$ Colaborador do projeto e Doutorando do Curso de Pós-Graduação em Botânica do Instituto Nacional de Pesquisas da Amazônia. Av. André Araújo 2936, Petrópolis, Manaus, AM. CEP. 69083-000 


\section{ACTA \\ AMAZONICA}

VALOR NUTRICIONAL DO MEL E POLEN

DE ABELHAS SEM FERRÃO DA REGIÃO AMAZÔNICA fortificantes e agentes bactericidas. Além de ser o adoçante natural e fonte de energia, o mel apresenta efeitos imunológicos, antibacteriano, antiinflamatório, analgésico, sedativo, expectorante e hiposensibilizador (Wiese, 1986). É produzido a partir do néctar e outras exsudações naturais das plantas que são coletadas, processadas e armazenadas pelas abelhas (Crane, 1985).

O pólen é o elemento masculino da flor e tem sido utilizado há muito tempo, principalmente entre adeptos da alimentação natural, como um suplemento da dieta humana (Dadant, 1966), provavelmente pela riqueza em relação a proteínas, lipídios, vitaminas e sais minerais (Schause, 1998, Silveira, 1996).

Os estudos analíticos para o mel e pólen tem sido realizados principalmente para as abelhas Apis mellifera e poucos são os estudos que tratam do valor nutricional dos produtos das abelhas sem ferrão. Deste modo, a presente proposta avaliou a composição centesimal do mel e pólen de espécies de abelhas nativas da região amazônica.

Amostras de pólen e mel foram coletadas entre os meses de Novembro a Dezembro de 2002 de cinco colônias de abelhas das espécies Melipona seminigra merrillae (jandaíra), Melipona compressipes manaosensis (jupará), Melipona rufiventris paraensis (uruçu boca de ralo), provenientes do meliponário da Fazenda Poranga no município de Itacoatiara - AM e Meliponário Abelhudo em Manaus - AM. O pólen foi acondicionado em frascos de polietileno, com tampa rosqueada, capacidade de $180 \mathrm{~mL}$, previamente higienizadas. As amostras de mel de abelhas sem ferrão foram retiradas dos favos com auxílio de uma seringa descartável e acondicionados em frascos de polietileno, da mesma forma que o pólen. Todo o material foi transportado até o Laboratório de Nutrição e FísicoQuímica de Alimentos da Coordenação de Pesquisa em Ciência da Saúde (CPCS), do Instituto Nacional de Pesquisas da Amazônia - INPA para a realização das análises.
As amostras em triplicata de pólen foram liofilizadas em liofilizador de marca EDWARDS módulo $4 \mathrm{~K}$ Freeze Dryer por oito horas para a determinação do teor de umidade e o mel seco em estufa à temperatura de $105^{\circ} \mathrm{C}$ até o peso constante, para a quantificação do teor de umidade (AOAC, 1995).

O teor de proteína em triplicata foi determinado pelo método Micro Kjeldahl para nitrogênio total, utilizando-se o fator de 6,25 para conversão de acordo com a AOAC (1995). A fração etérea (triplicata) em extrator intermitente de Soxhlet, tendo o éter de petróleo como solvente (AOAC, 1995). A determinação de cinzas ou resíduo mineral fixo (triplicata), por gravimetria em mufla a $550^{\circ} \mathrm{C}$ até peso constante segundo a AOAC (1995). Foi utilizada a análise de variância e para fins de comparação entre as médias das diferentes espécies de abelha o teste de Tukey com 5\% de probabilidade (Pimentel Gomes, 1987).

De acordo com as características físico-químicas, constatou-se que o mel das abelhas sem ferrão $M$. compressis é mais fluído e de cristalização lenta quando comparado com a Apis mellifera. Para fins de análise química foram consideradas as amostras das cinco (distintas) colônias e sob o ponto de vista nutricional, a concentração média de energia de 285,3 $\pm 18,7 \mathrm{kcal}$ em $100 \mathrm{~g}$ das amostras analisadas, ratifica o potencial do mel como fonte de energia, particularmente a M. rufiventris com 305,3 $\pm 2,4 \mathrm{kcal}$ em $100 \mathrm{~g}$ (Tabela 1).

O mel apresentou ainda uma concentração média de umidade na ordem de $28,6 \pm 4,6 \%$, sendo o maior percentual constatado na $M$. compressis $34,6 \pm 0,5 \%$ e a menor concentração na Melipona rufiventris paraensis 23,9 0,6 (Tabela 1). Valores similares ao da Melipona compressipes manaosensis $25,3 \pm 0,7$ foram registrados nas análises preliminares de características físicoquímicas de méis de Tiúba (Melípona compressipes) do Piauí 25\% (Souza \& Bazlen, 1998). O teor de proteína do mel foi extremamente baixo, com valores inferiores a 1\% (Tabela 1). O mesmo é extensivo às concentrações

Tabela 1 - Composição centesimal do mel de diferentes espécies de abelha e procedência, em 100g da matéria in natura.

\begin{tabular}{|c|c|c|c|c|c|c|}
\hline Espécies & $\begin{array}{c}\text { Melipona } \\
\text { compressipes } \\
\text { manaosensis } \\
\text { (Jupará) }\end{array}$ & $\begin{array}{l}\text { Melipona } \\
\text { rufiventris } \\
\text { paraensis } \\
\text { (Üruçu boca } \\
\text { de ralo) }\end{array}$ & $\begin{array}{c}\text { Melipona } \\
\text { compressipes } \\
\text { manaosensis } \\
\text { (Jupará) }\end{array}$ & $\begin{array}{c}\text { Melipona } \\
\text { seminigra } \\
\text { merrillae } \\
\text { (Jandaíra) }\end{array}$ & $\begin{array}{c}\text { Melipona } \\
\text { compressipes } \\
\text { manaosensis } \\
\text { (Jupará) }\end{array}$ & $\begin{array}{c}\text { Concentração } \\
\text { Media }\end{array}$ \\
\hline Procedência & $\begin{array}{l}\text { Manaus-AM, } \\
10 / 11 / 2000\end{array}$ & $\begin{array}{l}\text { Manaus-AM, } \\
10 / 11 / 2000\end{array}$ & $\begin{array}{l}\text { Manaus-AM, } \\
04 / 11 / 2000\end{array}$ & $\begin{array}{c}\text { Itacoatiara-AM, } \\
23 / 12 / 2000\end{array}$ & $\begin{array}{c}\text { Itacoatiara-AM, } \\
23 / 12 / 2000\end{array}$ & $\%$ \\
\hline Umidade (g) & $32,3 \pm 0,3^{b}$ & $23,9 \pm 0,6^{d}$ & $34,6 \pm 0,5^{a}$ & $27,0 \pm 1,3^{c}$ & $25,3 \pm 0,7^{c d}$ & $28,6 \pm 4,6$ \\
\hline Proteína (g) & $0,2 \pm 0,0^{d}$ & $0,4 \pm 0,0 b^{c}$ & $0,2 \pm 0,0^{d}$ & $0,4 \pm 0,0^{b}$ & $0,8 \pm 0,0^{a}$ & $0,4 \pm 0,2$ \\
\hline Cinzas (g) & $0,2 \pm 0,0^{c}$ & $0,2 \pm 0,0^{c}$ & $0,03 \pm 0,0^{d}$ & $0,3 \pm 0,0^{b}$ & $0,4 \pm 0,0^{a}$ & $0,2 \pm 0,1$ \\
\hline Lipídios (g) & $0,12 \pm 0,0^{c}$ & $0,18 \pm 0,0^{\mathrm{b}}$ & $0,07 \pm 0,0^{d}$ & $0,3 \pm 0,0^{a}$ & $0,09 \pm 0,0^{c d}$ & $0,15 \pm 0,09$ \\
\hline Glicídios (g) & $67,2 \pm 0,3^{c}$ & $75,5 \pm 0,6^{a}$ & $64,8 \pm 0,1^{c}$ & $72,4 \pm 1,5^{b}$ & $73,0 \pm 0,2^{\mathrm{ab}}$ & $70,6 \pm 4,4$ \\
\hline Energia (kcal) & $270,7 \pm 1,2^{c}$ & $305,3 \pm 2,4^{a}$ & $260,8 \pm 0,2^{d}$ & $293,9 \pm 6,0^{b}$ & $296,0 \pm 1,1^{a}$ & $285,3 \pm 18,7$ \\
\hline
\end{tabular}




\section{ACTA AMAZONICA}

VALOR NUTRICIONAL DO MEL E PÓLEN

DE ABELHAS SEM FERRÃO DA REGIÃO AMAZÔNICA de cinzas e lipídios (Tabela 1). De modo geral, os resultados das análises de mel, corroboram com os estudos de Dantas et al. (1998) no que se refere aos teores de umidade de 18,8 a $35,2 \%$ e cinzas $0,03 \%$ a $0,71 \%$ no mel de abelhas sem ferrão no Estado do Acre e proteína 0,51 $0,32 \%$ no mel da abelha urucu (Melípona scutellaris) na Bahia (Marchini et al., 1998). Os autores relatam que o mel de Meliponinae é propício à fermentação e, assim, deve ser consumido rapidamente. A região amazônica pela sua imensa diversidade de espécies de plantas presentes em diferentes ecossistemas apresenta também méis com características distintas. $\mathrm{O}$ mel aqui produzido é considerado na sua maioria silvestre ou heterofloral, proveniente de diversas fontes florais. Neste caso apresenta também uma riqueza maior de tipos de pólen do que outras regiões do Brasil.

As amostras de pólen de abelhas sem ferrão apresentaram umidade média de $36,9 \pm 11,1 \%$ com uma variação de $22,3 \pm 0,2 \%$ a 49,2 $\pm 0,09 \%$ (Tabela 2 ). Entretanto, em relação aos constituintes nutricionais do pólen, os resultados demonstraram uma concentração média substancial de proteína 19,5 $\pm 3,3 \%$, particularmente na espécie $M$. seminigra com 23,8 $\pm 0,3$ $\%$. O mesmo é extensivo ao teor de energia, tendo como contribuição as fontes de lipídios e glicídios (Tabela 2). O período de coleta coincidindo com o início das chuvas (inverno) e conseqüentemente com o maior armazenamento de pólen pelas abelhas, assim como, a presença de espécies de plantas que podem diferir de uma estação para outra são fatores que contribuem na maior ou menor concentração desses constituintes nutricionais. Salienta-se da necessidade de se quantificar o teor de fibra alimentar do pólen para não superestimar o teor energético (estudo em andamento).

Apesar da ausência de informações em relação à composição centesimal do pólen dessas abelhas sem ferrão, os resultados preliminares permitem concluir que a espécie M.seminigra apresentou um pólen com concentrações substanciais de proteína e lipídio e a M compressipes o maior teor de energia.

Quando comparado com alguns alimentos da região amazônica, como castanha do amazonas (20,7\%), peixes de um modo geral como tambaqui, sardinha, pacu e tucunaré com uma concentração média em torno de (20\%), (Aguiar, 1996), não se pode negar a riqueza deste componente protéico no pólen de abelhas sem ferrão.

O pólen da espécie $A$. mellifera da região de Piracicaba, SP da mesma forma que as abelhas sem ferrão contém quantidades apreciáveis de proteína: 21,3\%, lipídios 3,4\% e cinzas 2,9\% (Reis \& Marchini, 2000). O mesmo é extensivo às amostras de pólen apícola desidratado brasileiro com um teor de proteína na ordem

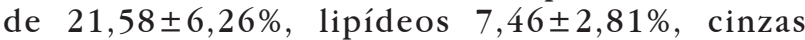
$2,18 \pm 0,65 \%$ e carboidratos $56,50 \pm 10,11 \%$ (AlmeidaMuradian \& Presoto, 2000), demonstrando que independente das espécies, o pólen é detentor de nutrientes essenciais como a proteína e energia.

O pólen tem despertado a atenção do homem pela riqueza dos seus constituintes nutricionais, a fim de que haja um aproveitamento de suas propriedades alimentícias na dieta humana. O mesmo é extensivo ao mel como fonte de energia. Portanto, estudos da incorporação destes produtos na dieta humana devem ser implementados, possibilitando uma nova fonte alternativa de alimento potencialmente nutritivo e saudável aos amazônidas.

\section{AGRADECIMENTOS}

A FINEP/ PPG-7 e PPI: 1-3100 pelo suporte financeiro, ao CNPq pela concessão da bolsa e George Nakamura pela revisão do Abstract.

Tabela 2 - Composição centesimal do pólen de diferentes espécies de abelha e procedência, em 100g da matéria in natura.

\begin{tabular}{|c|c|c|c|c|c|c|}
\hline Espécies & $\begin{array}{l}\text { Melipona } \\
\text { rufiventris } \\
\text { paraensis } \\
\text { (Uruçu boca } \\
\text { de ralo) }\end{array}$ & $\begin{array}{c}\text { Melipona } \\
\text { compressipes } \\
\text { manaosensis } \\
\text { (Jupará) }\end{array}$ & $\begin{array}{c}\text { Melipona } \\
\text { compressipes } \\
\text { manaosensis } \\
\text { (Jupará) }\end{array}$ & $\begin{array}{l}\text { Melipona } \\
\text { seminigra } \\
\text { merrillae } \\
\text { (Jandaíra) }\end{array}$ & $\begin{array}{c}\text { Melipona } \\
\text { compressipes } \\
\text { manaosensis } \\
\text { (Jupará) }\end{array}$ & $\begin{array}{c}\text { Concentração } \\
\text { Média }\end{array}$ \\
\hline Procedência & $\begin{array}{l}\text { Manaus-AM, } \\
10 / 11 / 2000\end{array}$ & $\begin{array}{l}\text { Manaus-AM, } \\
10 / 11 / 2000\end{array}$ & $\begin{array}{l}\text { Manaus-AM, } \\
\text { 04/11/2000 }\end{array}$ & $\begin{array}{c}\text { Itacoatiara-AM, } \\
\text { 23/12/2000 }\end{array}$ & $\begin{array}{c}\text { Itacoatiara-AM, } \\
23 / 12 / 2000\end{array}$ & $\%$ \\
\hline Umidade (g) & $49,2 \pm 0,0^{a}$ & $33,4 \pm 1,0^{b}$ & $22,3 \pm 0,2^{c}$ & $46,8 \pm 0,1^{a}$ & $33,0 \pm 1,6^{b}$ & $36,9 \pm 11,1$ \\
\hline Proteína (g) & $19,1 \pm 01^{c}$ & $17,1 \pm 0,5^{d}$ & $15,7 \pm 0,0^{e}$ & $23,8 \pm 0,3$ a & $22,0 \pm 0,9^{b}$ & $19,5 \pm 3,3$ \\
\hline Cinzas (g) & $1,8 \pm 0,1^{b}$ & $1,7 \pm 0,1^{b}$ & $2,6 \pm 0,1^{\mathrm{a}}$ & $1,8 \pm 0,2^{b}$ & $2,5 \pm 0,1^{a}$ & $2,1 \pm 0,4$ \\
\hline Lipídios (g) & $3,6 \pm 0,2^{b}$ & $9,3 \pm 0,03$ a & $1,9 \pm 0,1^{c}$ & $3,4 \pm 0,1^{b}$ & $1,9 \pm 0,1^{c}$ & $4,0 \pm 3,0$ \\
\hline Glicídios (g) & $26,9 \pm 1,3^{d}$ & $38,5 \pm 0,5^{c}$ & $57,4 \pm 0,1^{\mathrm{a}}$ & $24,2 \pm 0,5^{\mathrm{e}}$ & $40,6 \pm 0,1^{c}$ & $37,5 \pm 13,2$ \\
\hline Energia (kcal) & $216,4 \pm 3,8^{c}$ & $306,2 \pm 4,2^{a}$ & $309,8 \pm 0,8^{a}$ & $222,4 \pm 1,3 \mathrm{bc}$ & $267,4 \pm 6,6^{\mathrm{b}}$ & $264,4 \pm 44,4$ \\
\hline
\end{tabular}

As mesmas letras no sentido horizontal não diferem em nível de 5\% de probabilidade pelo teste de Tukey. 


\section{ACTA AMAZONICA}

VALOR NUTRICIONAL DO MEL E PÓLEN

DE ABELHAS SEM FERRÃO DA REGIÃO AMAZÔNICA

\section{BIBLIOGRAFIA CITADA}

Aguiar, J.P.L. 1996. Tabela de composição alimentos da Amazônia. Acta Amazonica 26(1/2):121-126.

Almeida-Muradian, L.B.; Presoto, A.E.F. 2000. Análise da composição centesimal de amostras de pólen apícola desidratado brasileiro. In: Anais XIII Congresso Brasileiro de Apicultura, Florianópolis-SC. Cd. ROM.

Association of Official Analytical Chemists. 1995. Official methods of analysis of the Association of Official Analytical Chemists. $17^{\mathrm{a}}$ ed., Arlington, USA, AOAC. 1141p

Crane, E. 1985. O livro do mel. São Paulo: Nobel. 226p.

Dadant, L. 1966. La Abeja y la colmeia. 4a ed., Guli, 936p.

Dantas, F.M.; Marques, D.D.; Oliveira, M.L.; Morato, E.F. 1998. Sobre os méis de abelhas indígenas sem ferrão (Hymenoptera, Apidae, Meliponinae) de Rio Branco, Acre. In: Congresso Brasileiro de Zoologia, 22. Recife. Anais... Recife: 1998. p.194.

Kerr, W.E., Carvalho, G.A., Nascimento, V.A. 1996. Abelba Uruçu: Biologia, Manejo e Conservação. Belo Horizonte: Acangaú. 144p.

Lajolo, F.M. 1995. As deficiências da composição de alimentos no Brasil. In:Anais, Simpósio das Instituições Brasileiras de Alimentação e Nutrição. p . 2-5.

Marchini, L.C.; Carvalho, C.A.L.; Alves, R.M.de O.; Teixeira, G.M.; Oliveira, P.C.,F.; Rubia, V.R. Características Fisico-Químicas de amostras de méis de abelha uruçu (Melipona scutellaris). In: Congresso Brasileiro de Apicultura, 12:1998. Salvador. Anais...Salvador, Confederação Brasileira de Apicultura, p. 201.

Pimentel Gomes, F. 1987. Curso de Estatística Experimental. $12^{\circ}$ ed. Piracicaba. $467 \mathrm{p}$.
Reis, V.D.A.; Marchini, L.C. Análises Físico-Químicas de amostras de pólen coletado por abelhas africanizadas (Apis mellifera 1.) em Piracicaba, SP. In: XIII Congresso Brasileiro de Apicultura. 2000. Florianópolis. Cd. ROM.

Schause, L.P. 1998. Aspectos práticos da produção de veneno, pólen e cera-controle de qualidade do pólen. In: Congresso Brasileiro de Apicultura, 12:1998. Salvador. Anais...Salvador, Confederação Brasileira de Apicultura, p. 119-122.

Silveira, F.A. 1996. A importância da palinologia nos estudos apícolas. In: Congresso Brasileiro de Apicultura, 11. 1996. Teresina. Anais... Teresina, Confederação Brasileira de Apicultura, p. 266-273.

Souza, D.C.; Bazlen, K. 1998. Análises preliminaries de características físico-químicas de méis de tiúba (Melípona compressipes) do Piauí. In: Congresso Brasileiro de Apicultura, 12:1998. Salvador. Anais...Salvador, Confederação Brasileira de Apicultura, p. 267.

Wiese, H. 1986. Nova Apicultura. 7ed. Porto Alegre: Agropecuária. 493p.

Yuyama, L.K.O., Aguiar, J.P.L., Macedo, S.H.M., Gioia, T., Yuyama, K., Fávaro, D.I.T., Afonso., C., Vasconcellos, M.B.A., Cozzolino, S.M.F. 1997. Determinação dos teores de elementos minerais em alimentos convencionais e não convencionais da região Amazônica pela técnica de análise por ativação com nêutrons instrumental. Acta Amazonica, 27 (3), 183-96.

\section{RECEBIDO EM 07/09/2003 \\ ACEITO EM 26/04/2004}

